\begin{tabular}{|c|c|}
\hline & $\begin{array}{c}\text { International Journal of Current Research } \\
\text { and Academic Review }\end{array}$ \\
\hline & $\begin{array}{r}\text { ISSN: 2347-3215 (Online) :,;Volume } 5, ;, ; \text { Number } 10 \text { (O) } \\
\text { Journal homepage: http://www.ijcrar.com }\end{array}$ \\
\hline
\end{tabular}

doi: https://doi.org/10.20546/ijcrar.2017.510.001

\title{
Production and Optimization of Extracellular Polysaccharides from Paenibacillus sp.
}

\author{
D.S. Deepa Dhas ${ }^{1}$, Mohammed A. Almalki ${ }^{2}$, Ponnuswamy Vijayaraghavan ${ }^{1 *}$ and Rakesh Varghese $^{3}$ \\ ${ }^{1}$ Bioprocess Engineering Division, Smykon Biotech Pvt Ltd, Nagercoil, Kanyakumari District, Tamil Nadu, India \\ ${ }^{2}$ Biological Sciences Department, College of Science, King Faisal University, Saudi Arabia \\ ${ }^{3}$ Department of Industrial Biotechnology, Bharath University, Selaiyur, Chennai 73, India \\ *Corresponding author
}

\section{Abstract}

Extracellular polymeric substances (EPSs) are produced by a wide array of bacteria for protection against aggregation, expression of virulence and adhesion. Growth associated EPS production was determined by Paenibacillus sp. in submerged fermentation. To improve the productivity and efficiency of EPS from Paenibacillus sp. the physical factors and nutrient components were optimized. The bacterial growth $(2.093 \mathrm{OD}$ at $600 \mathrm{~nm})$ was maximum after $36 \mathrm{~h}$ of incubation and EPS production (1.9 $\mathrm{mg} / \mathrm{ml}$ ) was high after 3 days of incubation at $37^{\circ} \mathrm{C}$. EPS production was found to be maximum at $\mathrm{pH} 7.0(2.31 \mathrm{mg} / \mathrm{ml})$, and at $40{ }^{\circ} \mathrm{C}(2.49 \mathrm{mg} / \mathrm{ml})$. Supplementation of $1 \%$ sucrose $(4.30 \mathrm{mg} / \mathrm{ml})$ supported more EPS production. Among the nitrogen sources, addition of yeast extract $(0.1 \%)$ supported maximum EPS production $(5.36 \mathrm{mg} / \mathrm{ml})$. Among inorganic sources, $\mathrm{NH}_{4} \mathrm{Cl}$ significantly influenced on EPS production.
\end{abstract}

\section{Introduction}

In recent years there has been a continuous search for novel polysaccharides from microorganisms. These biopolymers have been attracting much interest due to their potent application in cosmetic, food, pharmaceutical and oil industries, where they are used as stabilizing, thickening and emulsifying agents (Hayashi and Hayashi, 1996). Extracellular polysaccharides (EPSs) are extracellular biopolymers that are produced during the metabolic process of microorganisms such as fungi, bacteria and blue-green algae (Amjres et al., 2014). The EPSs could be either covalently associated with the cell surface forming a capsule, or be loosely attached, or totally secreted into the surrounding environment during the microbial cell growth (Yang et al., 2010). EPSs are either heteropolysaccharide or homopolysaccharide or biologically synthesized by varieties of bacteria. EPSs show many biological

\section{Article Info}

Accepted: 04 September 2017

Available Online: 20 October 2017

\author{
Keywords \\ Extracellular polysaccharide, \\ Paenibacillus sp. \\ Optimization, \\ Emulsifying agents
}

functions such as immuno-stimulating activity, antitumor activity (Vijayabaskar et al., 2011).

Production of EPS by various microbial groups including isolates belong to genus Bacillus have been widely investigated (Kim et al., 2002). Microorganisms are highly suited for EPS production than plants or algae, exhibiting good growth rates and being more amenable to manipulate, optimize the process conditions for better growth and EPS production (Moreno et al., 1998). Moreover, the high cost of the carbon sources such as sucrose, glucose and fructose and the cost of nitrogen sources directly influence on EPS production costs, which directly limit the potential of EPS market (Kumar et al., 2007). To obtain high EPS production, it is significant to optimize bioprocess conditions, which require an understanding of the various process parameters involved (Velasco et al., 2006). The productivity of EPSs has been found to vary with 
medium composition, environmental conditions including nitrogen source, carbon source and $\mathrm{pH}$ of the culture medium (Papagiannai, 2004).

Biopolymers have many applications in the pharmaceutical, food and other industries due to their physical properties and unique structure. The EPS produced by bacteria have been explored for various biotechnological applications such as anticoagulants, antitumor agents and wound healing properties (Sutherland, 1985). Modern pharmacological studies revealed that microbial polysaccharide possesses antiradiation, anti-oxidation, hyperglycemic, hypolipidemic activities, anti-tumour, anti-fatigue and other biological activities, which are hotspots of research on functional factors of health food and drugs (Tseng et al., 2008). The genus Paenibacillus consists of more than 89 species of neutrophilic, facultative anaerobes, periflagellated heterotrophic, endospore forming, and low $\mathrm{G}+\mathrm{C}$ content, Gram +ve bacilli, which were previously included within the genus Bacillus and further reclassified as a genus Paenibacillus (Ash et al., 1993). Bacteria belonging to the genus Paenibacillus have been isolated from variety of environments such as soil, water, insect larvae, food, vegetable matter, rhizospheres as well as clinical samples (Raza et al., 2011; Vijayaraghavan et al., 2016). Paenibacillus species produced a range of exopolysaccharides with diverse physiological and biotechnological functions. Paenibacillus sp. EPSs has attracted great interest because of their biotechnological potential in the treatment of wastewater and various industrial processes. Microorganisms are good and cheaper sources for EPS production compared with algae or plants because of their ability to grow in cheaper nutrient media within a few days, high growth rate, ease of manipulation and lower space requirement (Raza et al., 2011). Hence, there has been an increasing interest in producing EPSs from any new microbial isolates. Therefore, the aim of the present study was to isolate and screen EPS producing bacteria from the marine environment and to optimize the process parameters to enhance the EPS yield.

\section{Materials and Methods}

\section{Bacterial strain and cultural conditions}

Paenibacillus sp. IND8 was isolated previously from food and was used throughout the present study (Accession no: KF250416). This organism was grown on nutrient agar slants at $37{ }^{\circ} \mathrm{C}$ for $24 \mathrm{~h}$ and sub cultured regularly at 15 -day interval.

\section{Inoculum preparation}

A loopful culture of Paenibacillus sp. IND8 was inoculated into the nutrient broth medium $((\mathrm{g} / \mathrm{l})$; beef extract 1.5; peptone digest of animal tissue 5.0, sodium chloride 5.0, and yeast extract 1.5. The culture medium $\mathrm{pH}$ was adjusted to 7.0 using $1 \mathrm{~N} \mathrm{HCl} / \mathrm{NaOH}$. Further, the Erlenmeyer flask was incubated for $18 \mathrm{~h}$ at $37{ }^{\circ} \mathrm{C}$ in an orbital shaker $(150 \mathrm{rpm})$. The culture was then stored at 2 $-8{ }^{\circ} \mathrm{C}$ and used as the inoculums for further studies.

\section{Effect of fermentation period on the growth and EPS production}

About $0.2 \mathrm{ml}$ inoculum was introduced into a $100-\mathrm{ml}$ Erlenmeyer flask containing basal medium $((\mathrm{g} / \mathrm{l})$; yeast extract-0.1 g; glucose- $0.5 \mathrm{~g}$; $\mathrm{MgSO}_{4}-0.01 \mathrm{~g}$; peptone$0.25 \mathrm{~g} ; \mathrm{KH}_{2} \mathrm{PO}_{4}-0.05 \mathrm{~g}$; and $\mathrm{NaCl}-1.0 \mathrm{~g}$ ). The culture was incubated at $37{ }^{\circ} \mathrm{C}$ in an orbital shaker $(150 \mathrm{rpm})$ for 4 days. At every $24 \mathrm{~h}, 5 \mathrm{ml}$ culture was withdrawn and centrifuged at $10,000 \mathrm{rpm}$ for $15 \mathrm{~min}$ at $4{ }^{\circ} \mathrm{C}$. The EPS content of culture supernatant was assayed.

\section{Estimation of EPS}

The fermented medium was centrifuged (10000 rpm, 10 $\min , 4^{\circ} \mathrm{C}$ ) to separate the cell pellet and supernatant. The EPS in the cell free supernatant was precipitated with double volumes of acetone, kept overnight at $4{ }^{\circ} \mathrm{C}$ and then separated by centrifugation $\left(10000 \mathrm{rpm}, 4^{\circ} \mathrm{C}\right.$, $20 \mathrm{~min})$. Further, the precipitated EPS was completely dissolved in double distilled water and quantified. To $0.1 \mathrm{~mL}$ of EPS sample, $1 \mathrm{ml}$ of $5 \%(\mathrm{w} / \mathrm{v})$ phenol solution was added and mixed completely. Then, $5 \mathrm{~mL} \mathrm{H}_{2} \mathrm{SO}_{4}$ (concentrated) was added in the vial and the optical density was measured at $490 \mathrm{~nm}$ using a UV-vis spectrophotometer. The amount of EPS was then determined from the calibration curve using glucose as the standard.

\section{Effect of pH on EPS production}

Effect of $\mathrm{pH}$ on EPS production by Paenibacillus sp. IND8 was evaluated by adjusting the culture medium $\mathrm{pH}$ (5.0, 5.5, 6.0, 6.5, 7.0, 7.5, and 8.0) using $1 \mathrm{~N}$ $\mathrm{HCl} / \mathrm{NaOH}$. After sterilization, $500 \mu \mathrm{l}$ of inoculum was introduced into an Erlenmeyer flask. Then these flasks were incubated for 3 days at $37^{\circ} \mathrm{C}$. After 3 days of incubation, the cells were centrifuged and harvested. The 
culture supernatant was precipitated with acetone and EPS content was assayed.

\section{Effect of different temperature}

Effect of temperature on EPS production was carried out by inoculating $500 \mu \mathrm{l}$ of inoculum into the nutrient broth medium at various temperatures for 3 days at $37^{\circ} \mathrm{C}$. The temperatures maintained were 25 to $50{ }^{\circ} \mathrm{C}$. After 3 days of incubation, the cell free extract was precipitated with acetone and EPS content was assayed.

\section{Effects of different carbon sources}

The effect of carbon sources (1\%) on the production of EPS was carried out by supplementing carbon sources such as dextrose, sucrose, maltose, lactose and glucose. After 3 days of incubation, the cell free extract was precipitated with acetone and EPS content was assayed.

\section{Effect of nitrogen sources on EPS production}

The effect of nitrogen sources $(0.1 \%)$ on EPS production was evaluated by supplementing nitrogen sources such as yeast extract, gelatine, oat meal, skimmed milk, casein and ammonium chloride in the nutrient broth medium. The medium was inoculated with $500 \mu \mathrm{l}$ inoculum. After $72 \mathrm{~h}$, the culture was centrifuged (10,000 rpm, $10 \mathrm{~min})$. The culture supernatant was precipitated with acetone and EPS was assayed.

\section{Effects of amino acids on EPS production}

The effect of amino acids at $0.1 \%(\mathrm{w} / \mathrm{v})$ concentration (Glutamine, Glycine, Methionine Cysteine and Alanine) was supplemented into the production medium individually to determine the effect of amino acids on EPS production. After $72 \mathrm{~h}$, the culture was centrifuged $(10,000 \mathrm{rpm}, 10 \mathrm{~min})$. The culture supernatant was precipitated with acetone and EPS was assayed.

\section{Results and Discussion}

EPSs are synthesized by the bacterial cells and excreted out to the outer environment. Little information is available on the biosynthesis of EPSs from microbes (Sutherland, 1996). In the present study the process parameters were optimized to enhance the production of EPSs. To improve the productivity and efficiency of EPS from Paenibacillus sp. the physical factors and nutrient components were optimized. Many researchers have evaluated the effects of process parameters on the maximal production of EPSs to optimize the process conditions, such as temperature, $\mathrm{pH}$ and medium composition (Rafigh et al., 2014; Raza et al., 2011). Studies of EPS have demonstrated that the composition of the culture medium plays an important role in EPS production (Liu et al., 2009).

It was previously reported that the production of EPS was associated with cell growth (Raza et al., 2011; Wang et al., 2011; Liang et al., 2014). In the present study the bacterial growth $(2.093 \mathrm{OD}$ at $600 \mathrm{~nm})$ was maximum after $36 \mathrm{~h}$ of incubation and EPS production $(1.9 \mathrm{mg} / \mathrm{ml})$ was high after $72 \mathrm{~h}$ incubation at $37{ }^{\circ} \mathrm{C}$. Rafigh et al., (2014) reported that when the initial $\mathrm{pH}$ of the culture medium was increased from 5.5 to 7.0 , there was a dramatic increase in curdlan gum and biomass production in Paenibacillus sp. approximately $39.0 \%$ and $5.0 \%$, respectively. Moreover, higher $\mathrm{pH}$ values $(>\mathrm{pH}$ 8.5) caused a decrease in EPS production. In the present study, EPS production was found to be maximum at pH $7.0(2.31 \mathrm{mg} / \mathrm{ml})$. The EPSs from Paenibacillus sp. IND8 were in agreement with earlier study that for EPS production by $P$. polymyxa KCTC $8648 \mathrm{P}$, the optimum $\mathrm{pH}$ value of 7.0 was previously reported (Lee et al., 1997). In the present study EPS production was high when the organism was incubated at $40{ }^{\circ} \mathrm{C}(2.49 \mathrm{mg} / \mathrm{ml})$. Fermentation temperature is one of the critical factors for the production of EPS (Liu et al., 2009). Rafigh et al., (2014) reported that EPS production increased rapidly when the incubation temperature varied from 30 to $40{ }^{\circ} \mathrm{C}$ and then slightly increased as the fermentation proceeded from 40 to $50{ }^{\circ} \mathrm{C}$.

Many carbon sources namely, glucose, sucrose, maltose, lactose, and dextrose were used to determine the production of EPS. Supplementation of $1 \%$ sucrose (4.30 $\mathrm{mg} / \mathrm{ml}$ ) supported more EPS production. The other carbon sources such as maltose, glucose lactose, dextrose supported $2.4 \mathrm{mg} / \mathrm{ml}, 3.9 \mathrm{mg} / \mathrm{ml}, 3.2 \mathrm{mg} / \mathrm{ml}$, and 2.9 $\mathrm{mg} / \mathrm{ml}$, respectively (Fig. 1). This result was in consistent with the findings of earlier findings (Lee et al., 1997). Among the nitrogen sources, addition of yeast extract $(0.1 \%)$ supported maximum EPS production (5.36 $\mathrm{mg} / \mathrm{ml})$. Addition of other nitrogen sources such as oat meal $(1.2 \mathrm{mg} / \mathrm{ml})$, skim milk $(3.4 \mathrm{mg} / \mathrm{ml})$, and casein $(2.87 \mathrm{mg} / \mathrm{ml}$ ) also supported EPS production (Fig. 2).

Various nitrogen sources were employed for their effects on EPS production from the isolate. It was previously reported that organic nitrogen sources increased high amount of EPS than inorganic nitrogen substrates. 
Fig.1 Effect of fermentation period on EPS production by Paenibacillus sp.

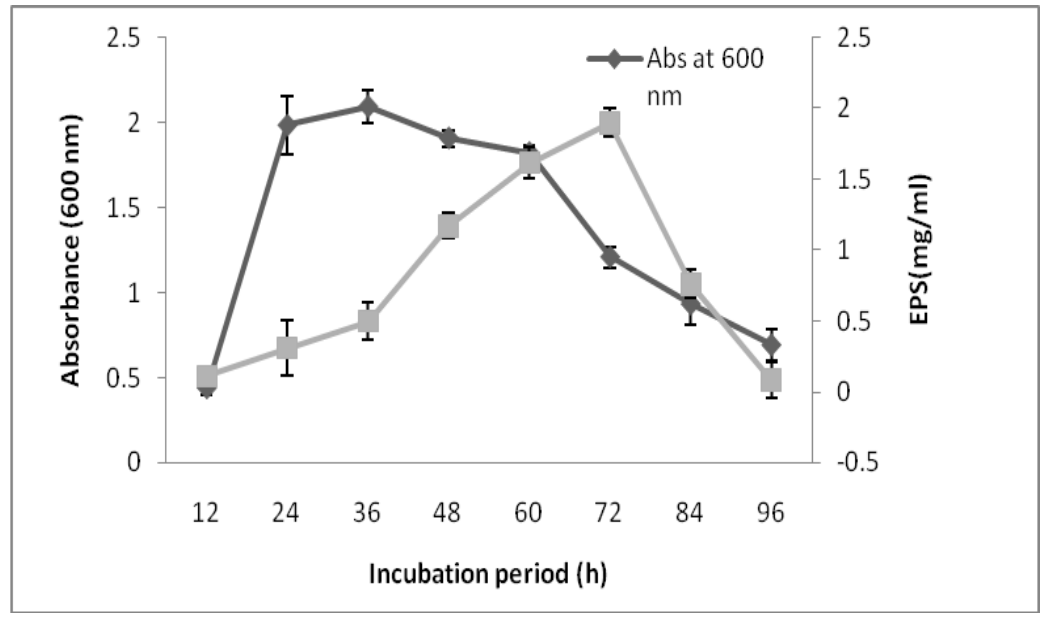

Fig.2 Effect of pH on EPS production by Paenibacillus sp.

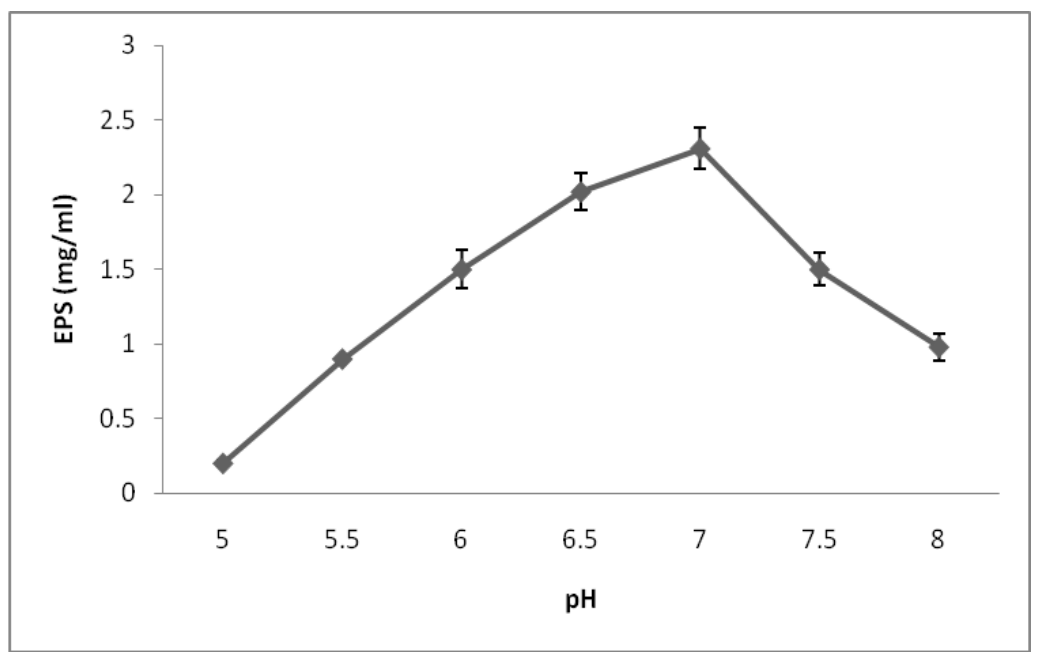

Fig.3 Effect of temperature on EPS production by Paenibacillus sp.

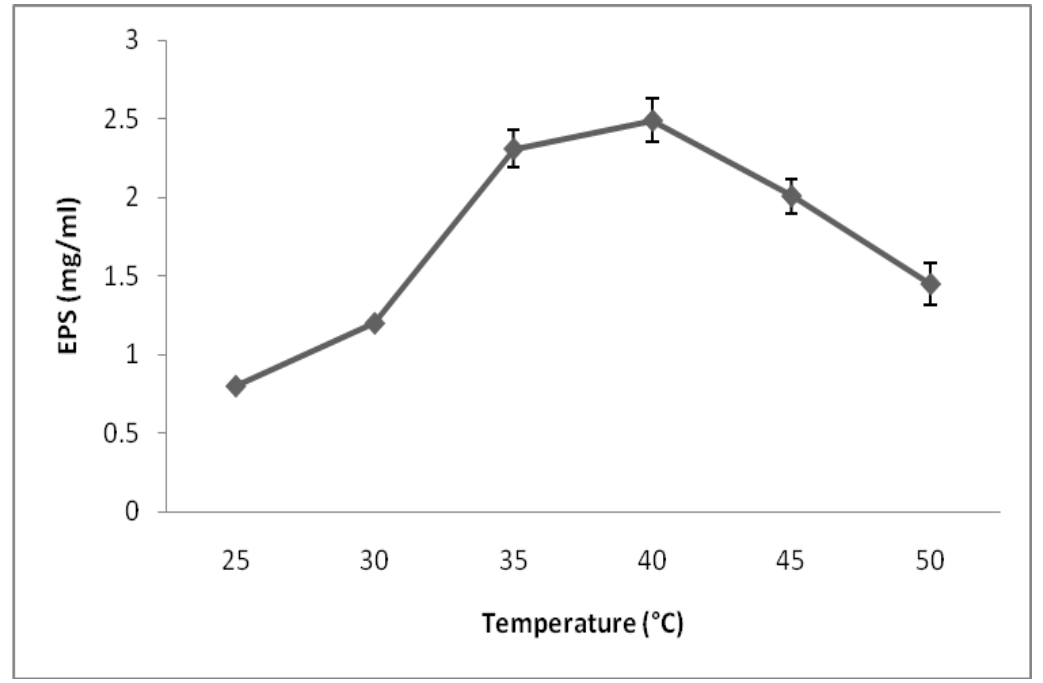


Fig.4 Effect of carbon sources on EPS production by Paenibacillus sp.

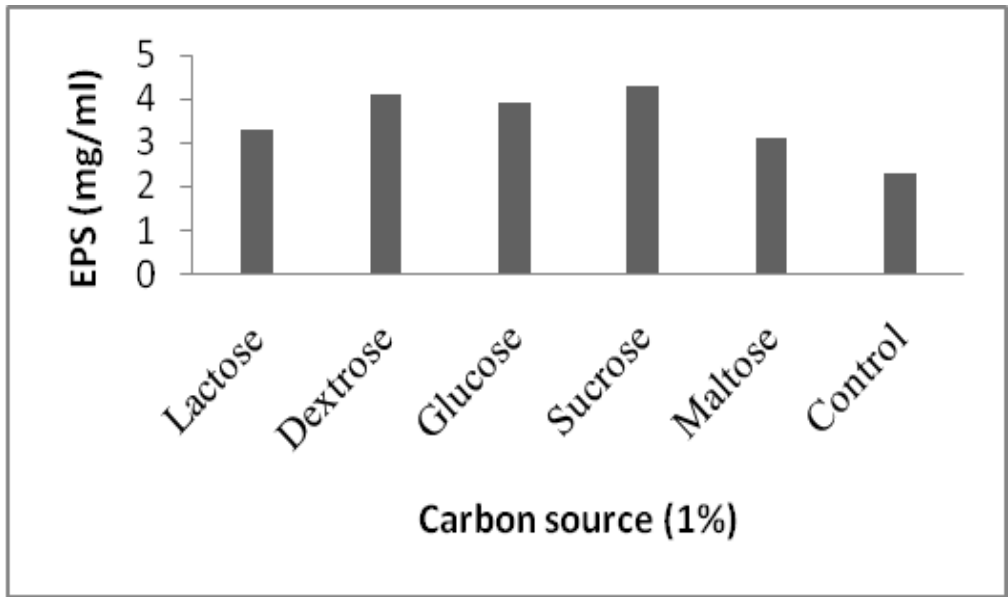

Fig.5 Effect of nitrogen sources on EPS production by Paenibacillus sp.

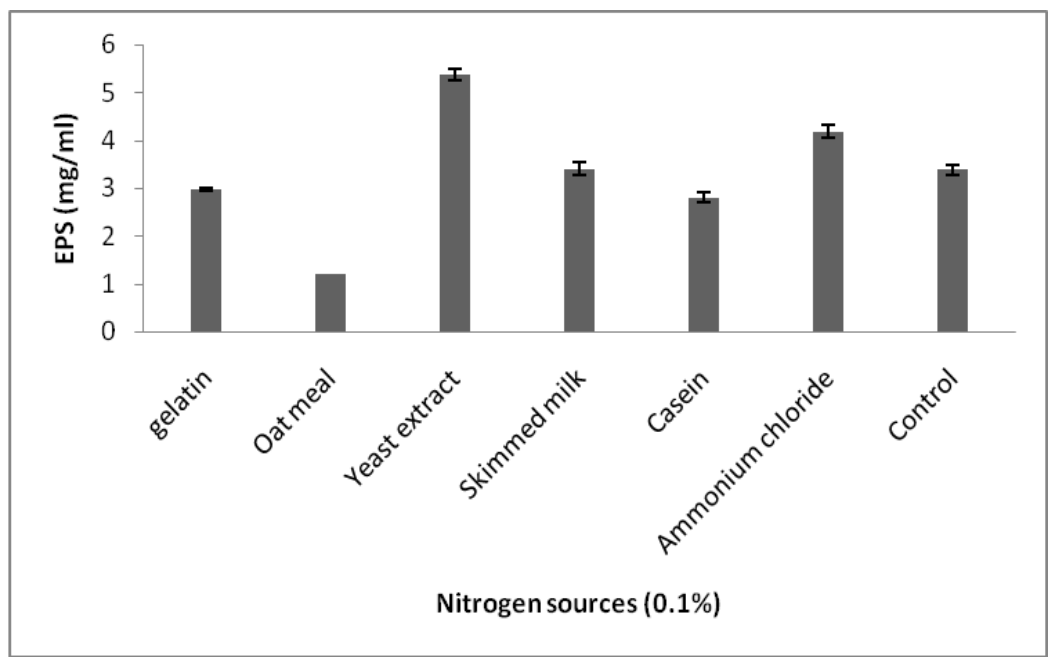

Fig.6 Effect of aminoacids on EPS production from Paenibacillus sp.

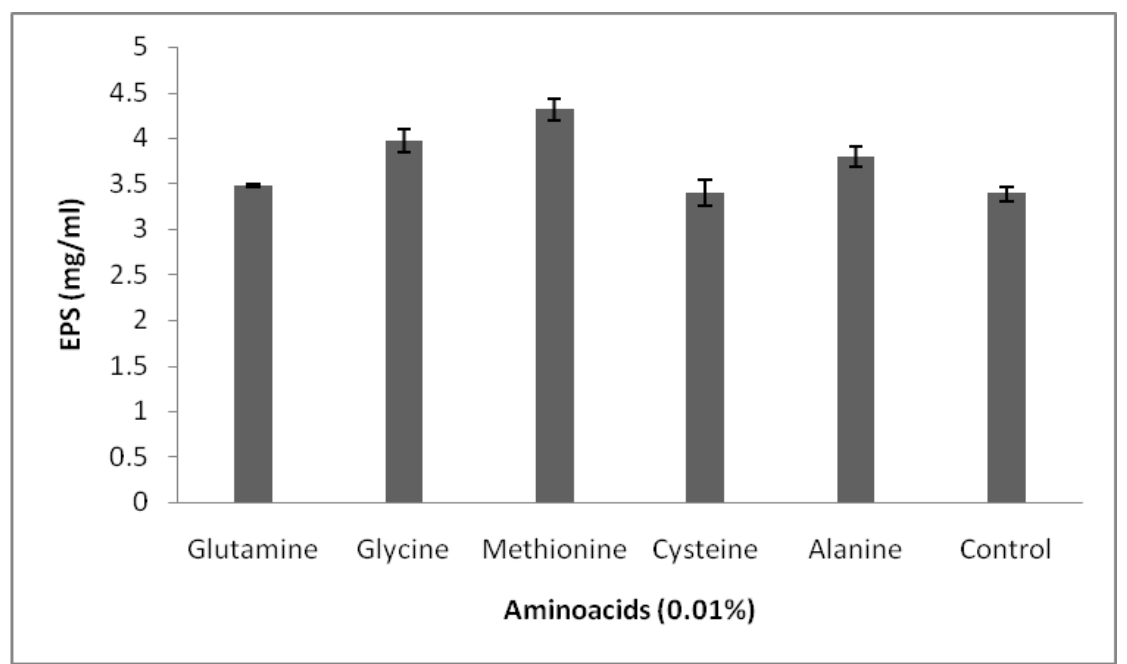


Yeast extract was found to produce the maximum amount of EPS than inorganic nitrogen sources. Among inorganic sources, $\mathrm{NH}_{4} \mathrm{Cl}$ significantly influenced on EPS production. Reports suggest that nitrogen limitation and maximum amounts of carbon in the medium could yield a maximum amount of EPS in the culture medium (Degeest and de Vuyst, 1999). The carbon sources such as, glucose, sucrose were mainly used for the production of EPS (Liu et al., 2009). Many authors have reported that the production of EPS is the culture medium containing carbon and nitrogen sources. In addition, the initial $\mathrm{pH}$ of the culture medium and incubation temperature are both important and may significantly affect the uptake of different nutrients, the cell growth, an EPS production (Rafigh et al., 2014).

In the present study, EPS production was found to be maximum in the culture medium containing methionine, followed by glycine. Vitamins showed a significant effect on EPS production. Aminoacids and vitamins are required for growth of bacteria and EPSs formation, and might have a significant role in the cellular metabolism, especially as precursors for EPS synthesis (Grobben et al., 1998). In B. subtilis strain 51, the growth and EPS production have been significantly influenced by methionine, isoleucine, leucine, glycine, tryptophan, cystine and alanine (Osadchaya et al., 1997).

\section{References}

Amjres, H., Béjar, V., Quesada, E., Carranza, D., Abrini, J., Sinquin, C., et al., (2014). Characterization of haloglycan, an exopolysaccharide produced by Halomonas stenophila HK30. Int J Biol Macromol., 72: 117-124.

Ash, C., Priest, F.G., Collins, M.D. 1993. Molecular identification of rRNA group 3 bacilli (Ash, Farrow, Wallbanks and Collins) using a PCR probe test. Proposal for the creation of a new genus Paenibacillus. Antonie Van Leeuwenhoek. 64(3-4): 253-260.

Degeest, B., de Vuyst, L. 1999. Indication that the nitrogen source influences both amount and size of exopolysaccharides produced by Streptococcus thermophilus LY03 and modelling of the bacterial growth and exopolysaccharide production in a complex medium. Appl Env Microbiol., 65: 28632870.

Grobben, G.J., Chin-Joe, I., Kitzen, V.A. et al., 1998. Enhancement of exopolysaccharide production by Lactobacillus delbrueckii subsp. bulgaricus NCFB
2772 with a simplified defined medium. Appl Environ Microbiol., 64: 1333-1337.

Hayashi, T., Hayashi, K. 1996. Calcium spirulan, an inhibitor of enveloped virus replication, from a bluegreen alga Spirulina platensis. $J$ Nat Prod., (Lloydia) 59: 83-87.

Kim, S.W., $\quad$ Hwang, H.J., $\quad$ Park, J.P., Cho, Y.J., Song, C.H., Yun, J.W. 2002. Myelial growth and exo-biopolymer production by submerged culture of various edible mushrooms under different media. Lett Appl Microbiol., 34: 56-61.

Kumar, A.S., Mody, K., Jha, B. 2007. Bacterial exopolysaccharides - a perception. J Basic Microbiol., 47: 103-117.

Lee, I.Y., Seo, W.T., Kim, G.J., Kim, M.K., Ahn, S.G., Kwon, G.S., Park, Y.H. 1997. Optimization of fermentation conditions for production of exopolysaccharide by Bacillus polymyxa. Bioprocess Eng., 16: 71-75.

Liang TW, Wu CC, Cheng WT, Chen YC, Wang CL, Wang IL, Wang SL (2014). Exopolysaccharides and antimicrobial biosurfactants produced by Paenibacillus macerans TKU029. Appl Biochem Biotechnol., 172(2): 933-950.

Liu, J., Luo, J., Ye, H., Sun, Y., Lu, Z., Zeng, X. 2009. Production, characterization and antioxidant activities in vitro of exopolysaccharides from endophytic bacterium Paenibacillus polymyxa EJS3. Carbohydr Polym., 78: 275-281.

Moreno, J., Vargas, M.A., Olivares, H., Rivas, J., Guerrero, M.G. 1998. Exopolysaccharide production by the cyanobacterium Anabaena sp. ATCC 33047 in batch and continuous culture. $J$ Biotechnol., 60: 175-182.

Osadchaya, A.I., Kudryavtsev, V.A., Kozachko, I.A, et al., 1997. Nitrogen nutrition of strains of aerobic spore-forming bacteria under conditions of submerged cultivation. Prikl Biokhim Mikrobiol., 33:433-438.

Papagianni, M. 2004. Fungal morphology and metabolite production in submerged mycelial processes. Biotechnol Adv., 22: 189-259. 10.1016/j.biotechadv.2003.09.005

Rafigh, S.M., Yazdi, A.V., Vossoughi, M., Safekordi, A.A., Ardjmand, M. 2014. Optimization of culture medium and modeling of curdlan production from Paenibacillus polymyxa by RSM and ANN. Int $J$ Biol Macromol., 70: 463-473.

Raza, W., Makeen, K., Wang, Y., Xu, Y., Qirong, S. 2011. Optimization, purification, characterization and antioxidant activity of an extracellular 
polysaccharide produced by Paenibacillus polymyxa SQR-21. Bioresour Technol., 102(10):6095-6103.

Sutherland, I.W. 1985. Biosynthesis of polysaccharides. Ann Review Microbiol., 39: 243-270.

Sutherland, I.W. 1996. Extracellular polysaccharides. In: Rhem HJ, Reed G, editors. Biotechnology. Vol. 6. VCH; Weinheim: pp. 615-57.

Tseng, Y., Yang, J., Mau, J. 2008. Antioxidant properties of polysaccharides from Ganoderma tsugae. Food Chem., 107: 732- 738.

Velasco, S., Arskod, E., Paese, M., Grage, H., Iraztorza, A., Radstrom, P., van Niel, E.W.J. 2006. Environmental factors influencing growth and exopolysaccharide formation by Pediococcus parvulus 2.6. Int J Food Microbiol., 111: 252-258.

Vijayabaskar, P., Babinastarlin, S., Shanka, T., Sivakumar, T., Anandapandian, K.T.K. 2011. Quantification and characterization of exopolysaccharides from Bacillus subtilis (MTCC 121). Adv Biol Res., 5: 71-76.

Vijayaraghavan, P., Vincent, S.G.P., Valan Arasu, M. 2016. Purification, Characterization of a Novel Fibrinolytic Enzyme from Paenibacillus sp. IND8, and its in Vitro Thrombolytic Activity. South Ind $J$ BIol Sci., 2(4): 434-444. DOI: 10.22205/sijbs/2016/v2/i4/103450

Wang, C.L., Huang, T.H., Liang, T.W., Fang, C.Y., Wang, S.L. 2011. Production and characterization of exopolysaccharides and antioxidant from Paenibacillus sp. TKU023. N Biotechnol., 28: 559565.

Yang, Z., Li, S., Zhang, X., Zeng, X., Li, D., Zhao, Y,.et al., 2010. Capsular and slime- polysaccharide production by Lactobacillus rhamnosus JAAS8 isolated from Chinese sauerkraut: Potential application in fermented milk products. J Biosci Bioeng., 110:53-57.

\section{How to cite this article:}

Deepa Dhas, D.S., Mohammed A. Almalki, Ponnuswamy Vijayaraghavan and Rakesh Varghese. 2017. Production and Optimization of Extracellular Polysaccharides from Paenibacillus sp. Int.J.Curr.Res.Aca.Rev. 5(10), 1-7. doi: https://doi.org/10.20546/ijcrar.2017.510.001 